\title{
BIOMIMICRY AS A DESIGN APPROACH FOR ADAPTATION
}

\author{
*Reem Elsamadisy, Alaa Eldin Sarhan, Yasser Farghaly and Amal Mamdouh \\ Arab Academy for Science, Technology and Maritime Transport, College of Engineering and \\ Technology, Alexandria, \\ *Corresponding author Email: reem_elsamadisy@hotmail.com,
}

\begin{abstract}
Biomimicry, where flora, fauna or entire ecosystems are emulated as a basis for design, is a growing area of research in the fields of architecture and engineering. This is due to both the fact that it is an inspirational source of possible new innovation and because of the potential it offers as a way to create a more sustainable and even regenerative built environment.

Nature provides a large database of adaptation strategies that can be implemented in design in general, and in the design of building envelopes in particular. The widespread and practical application of biomimicry as a design method remains however largely unrealized. Through literature review, and an examination of existing biomimetic technologies, this paper elaborates on distinct approaches to biomimetic design that have evolved. Biomimicry origins, levels and adaptation principles are discussed.It is hypothesized that applying biomimetics to architectural designs that incorporates an understanding of organisms' ecosystems' adaptive mechanisms could become a tool for creating a built environment that goes beyond simply sustaining current conditions to a restorative practice where the built environment becomes an adaptable and a vital component in the integration with and regeneration of natural ecosystems.
\end{abstract}

KEYWORDS: Biomimicry, Bio-Inspired Design, Adaptation, Biomimetic Architecture, Ecosystems

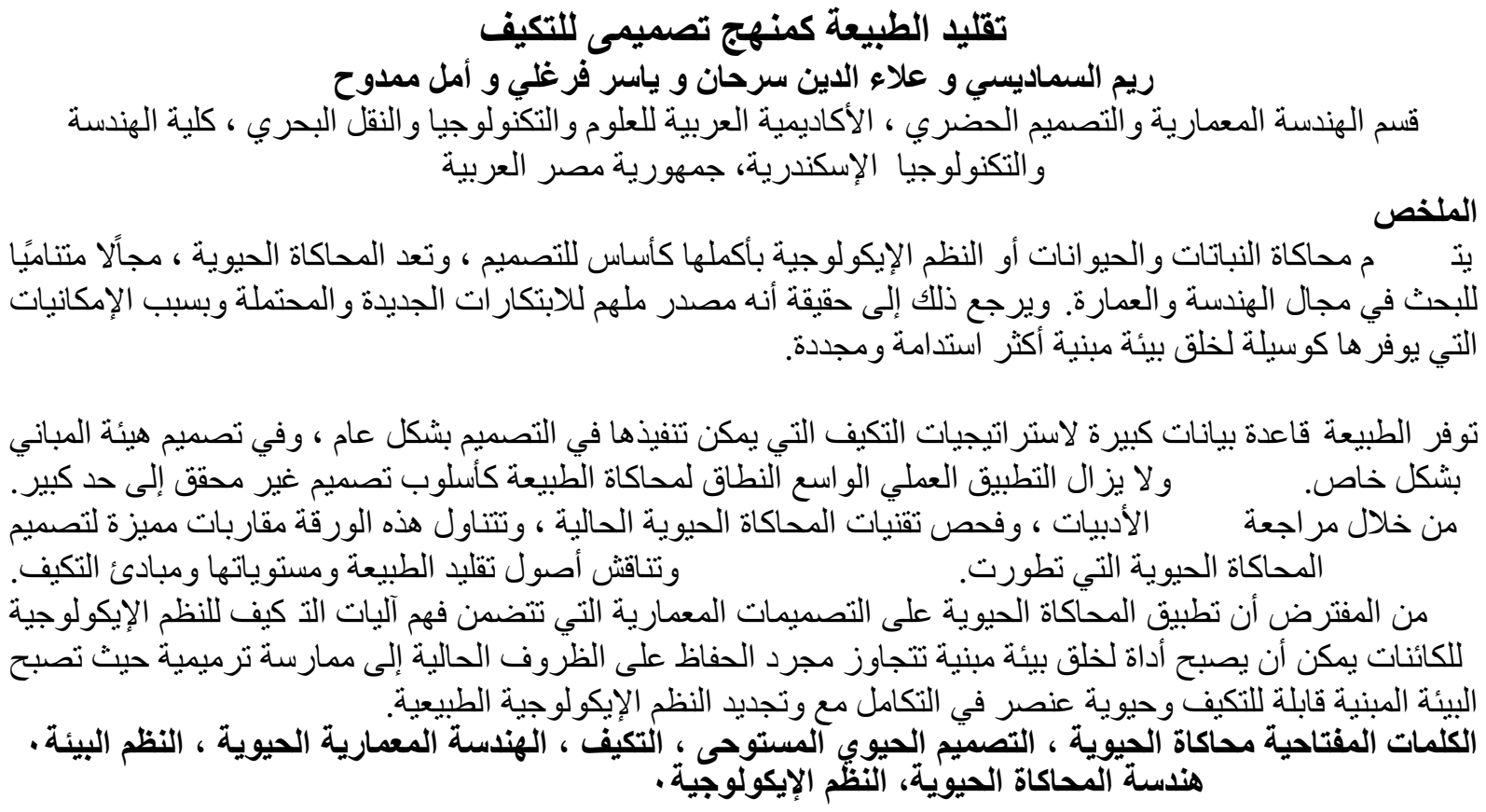

توفر الطبيعة قاعدة بيانات كبيرة لاستر اتيجيات التكيف التي يمكن تنفيذها في التصميم بشكل عام ، وفي تصميم التيم هيئة المباني

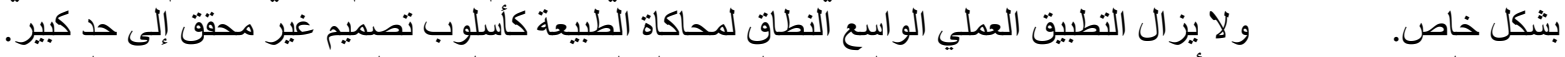




\section{INTRODUCTION}

Biomimicry is derived from the Greek, bios meaning life, and mimesis meaning to imitate. Other used terminologies include biomimetics, bio-inspired, bionic, or bionics. In biomimetics, solutions are obtained by emulating strategies, mechanisms, and principles found in nature. Nature provides a large database of adaptation strategies that can be implemented in design in general, and in the design of building envelopes in particular. Several benefits are identified for applying biomimetics to solving building problems, such as enhancing creativity and innovation [1-3]; optimizing resource (i.e., materials and energy) use in buildings [4]; lowering pollution, benefiting health, and mitigating urban heat island effects [5]; and providing a foundation for environmentally responsive developments [6-10].

Although various forms of biomimicry or bio-inspired design are discussed by researchers and professionals in the field of sustainable architecture [11-12], the widespread and practical application of biomimicry as an architectural design method remains largely unrealized. Examples of successful biomimicry that have progressed past the concept and development stage are typically of products or materials, rather than of buildings or building systems, and tend to mimic an aspect of a single organism (fig. 9 and 10).

A growing body of international research on biomimicry in relation to the built environment identifies various obstacles to the employment of such a methodology. One barrier of particular note is the lack of a clearly defined approach to biomimicry that architectural designers can initially employ [13].

This paper aims to discuss and illustrate biomimicry as an adaptive design approach. Current applications of biomimicry in different fields is elaborated. Biomimicry origins, levels and adaptation principles are explained. It is apparent that distinct approaches to biomimetic design exist, each with inherent advantages and disadvantages. These diverse approaches may have markedly different outcomes in terms of overall sustainability. While some designers and scientists employ biomimicry specifically as a method to increase the sustainability of what they have created, biomimicry is also used in some cases simply as a source of novel innovation [14].

\section{Historical Origins}

The term biomimicry appeared as early as 1982 and was popularized by scientist and author Janine Benyus in her 1997 book Biomimicry: Innovation Inspired by Nature. Biomimicry is defined in her book as a "new science that studies nature's models and then imitates or takes inspiration from these designs and processes to solve human problems". Benyus suggests looking to Nature as a "Model, Measure, and Mentor" and emphasizes sustainability as an objective of biomimicry.

- Nature as Model: Biomimicry is a new science that studies nature's models and them imitates or takes inspiration from these designs and processes to solve human problems, e.g., a solar cell inspired by a leaf.

- Nature as Measure: Biomimicry uses an ecological standard to judge the "rightness" of our innovations. After 3.8 billion years of evolution, nature has learned: What works. What is appropriate. What lasts.

- Nature as mentor: Biomimicry is a new way of viewing and valuing nature. It introduces an era based not on what we can extract from the natural world, but on what we can learn from it.

Problem solving has been inspired by nature since the Stone Age. Critics and philosophers since ancient Greece have looked to natural organisms as offering perfect models of that harmonious balance and proportion between the parts of a design which is synonymous with the classical ideal of beauty. The qualities of wholeness, of integrity, of a unity in structure such that the parts all contribute to the effect or purpose of the whole, and no part may be removed without some damage to the whole - these are central concepts in the aesthetics and in the natural history of Aristotle, and are characteristics in the Aristotelian view both of living beings and of the best works of art.

Leonardo da Vinci considered it essential to observe the anatomy and flying techniques of 
birds to create a flying machine (as shown in fig. 1). Although his machine was never completed, the mere principle of being inspired by nature introduces da Vinci as a biomimicry pioneer along with the Wright Brothers, who derived their inspiration from flying pigeons to construct the first airplane.
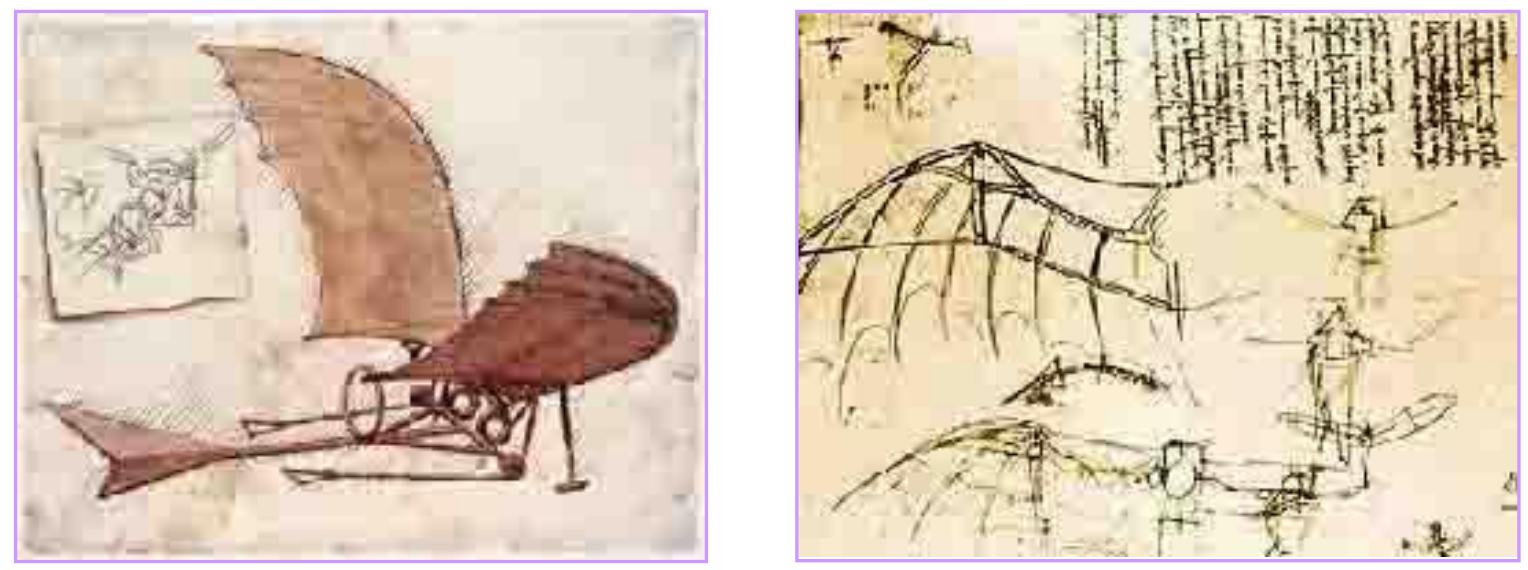

Fig. 1. Leonardo Da Vinci's drawings for the flying machine; one of earliest Biomimetic designs in the 13th century.

Architects and designers have looked to biology for inspiration since the beginnings of the science in the early nineteenth century. They have sought not just to imitate the forms of plants and animals, but to find methods in design analogous to the processes of growth and evolution in nature. Biological ideas are prominent in the writings of many modern architects, of whom Le Corbusier and Frank Lloyd Wright are just the most famous. Le Corbusier declared biology to be "the great new word in architecture and planning."

The trouble with biological analogy in architecture in the past is that much of it has been of a superficial picture-book sort: "artistic" photos of the wonders of nature through a microscope, juxtaposed with buildings or the products of industrial design. But analogy at a deeper level can be a most fundamental source of understanding and of scientific insight, as many writers on that subject have pointed out.

Although there is much that is completely new in recent "biological" developments in the practice and theory of design, this work does nevertheless often tend to echo or reinterpret ideas in the earlier history of biological analogy. Modern research in "biomimetics" (engineering analysis of organisms and their behavior with a view to applying the same principles in design) gives a new name and new rigor to what went under the banner of "biotechnique" or "biotechnics" in the 1920s and 1930s.

\section{Current Applications of Biomimicry}

Through basic research in the field of biology in combination with new technological advances, biomimicry studies the processes, functional solutions, and optimization of resources that natural systems and structures possess. Biomimicry has solved problems in fields such as transportation, car industry, medicine, communication and energy. Few examples of the integration of biomimicry in different scientific fields are illustrated in this section.

\section{Transportation}

The Shinkansen Bullet Train was the fastest train in the world, traveling 200 miles per hour. The Problem was that Air pressure changes produced large thunder claps every time the train emerged from a tunnel, causing residents one-quarter a mile away to complain. The Shinkansen train's chief engineer and a passionate bird-watcher, used his knowledge of the splash-less water entry of kingfishers and silent flight of owls to decrease the sound generated by the trains. 


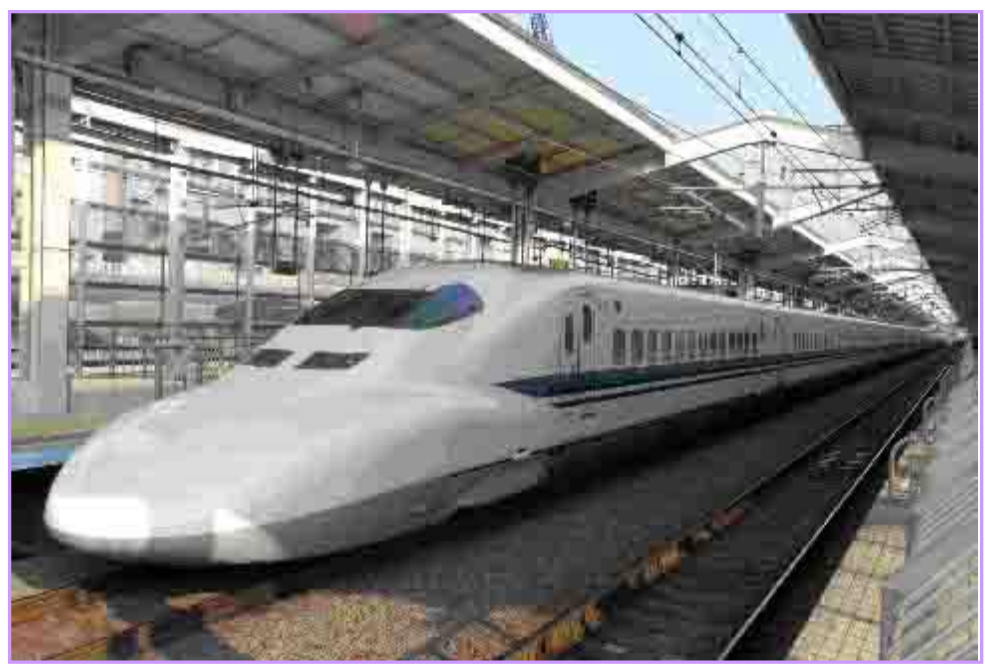

Fig. 2. the Shinkansen bullet train

Kingfishers move quickly from air, a low-resistance (low drag) medium, to water, a highresistance (high drag) medium. The kingfisher's beak provides an almost ideal shape for such an impact. The beak is streamlined, steadily increasing in diameter from its tip to its head. This reduces the impact as the kingfisher essentially wedges its way into the water, allowing the water to flow past the beak rather than being pushed in front of it (as shown in fig. 3). Because the train faced the same challenge, moving from low drag open air to high drag air in the tunnel, the forefront of the Shinkansen train was designed based on the beak of the kingfisher. Modeling the front-end of the train after the beak of kingfishers, which dive from the air into bodies of water with very little splash to catch fish, resulted not only in a quieter train, but $15 \%$ less electricity use even while the train travels $10 \%$ faster.

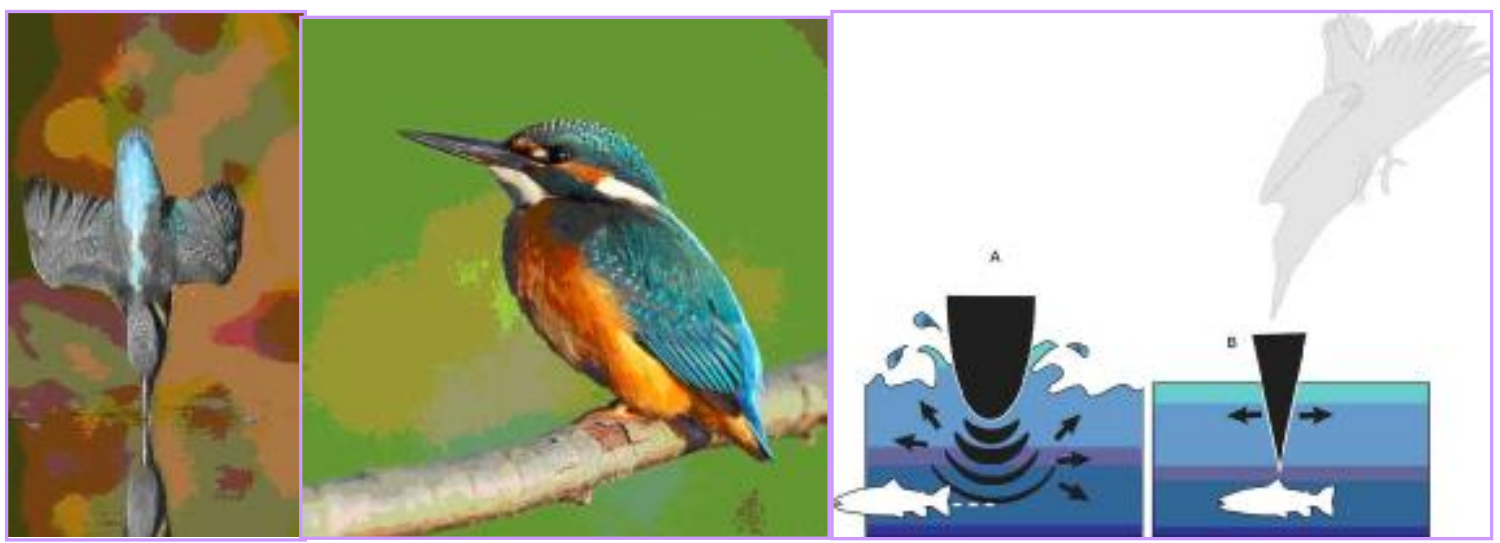

Fig. 3. If a kingfisher had a rounded beak, such as on the left, it would push water ahead of it, scaring or displacing the prey. Instead, the wedge-shaped beak and head (right) enters the water without a splash, increasing the changes of a successful hunt.

Engineers were also able to reduce the pantograph's noise by adding structures to the main part of the pantograph to create many small vortices. This is similar to the way an owl's primary feathers have serrations that create small vortices instead of one large one. Owls are known as silent predators of the night, capable of flying just inches from their prey without being detected. The quietness of their flight is owed to their specialized feathers. When air rushes over an ordinary wing, it typically creates a "gushing" noise as large areas of air turbulence build up. But the owl has a few ways to alter this turbulence and reduce its noise (as shown in fig. 4). 

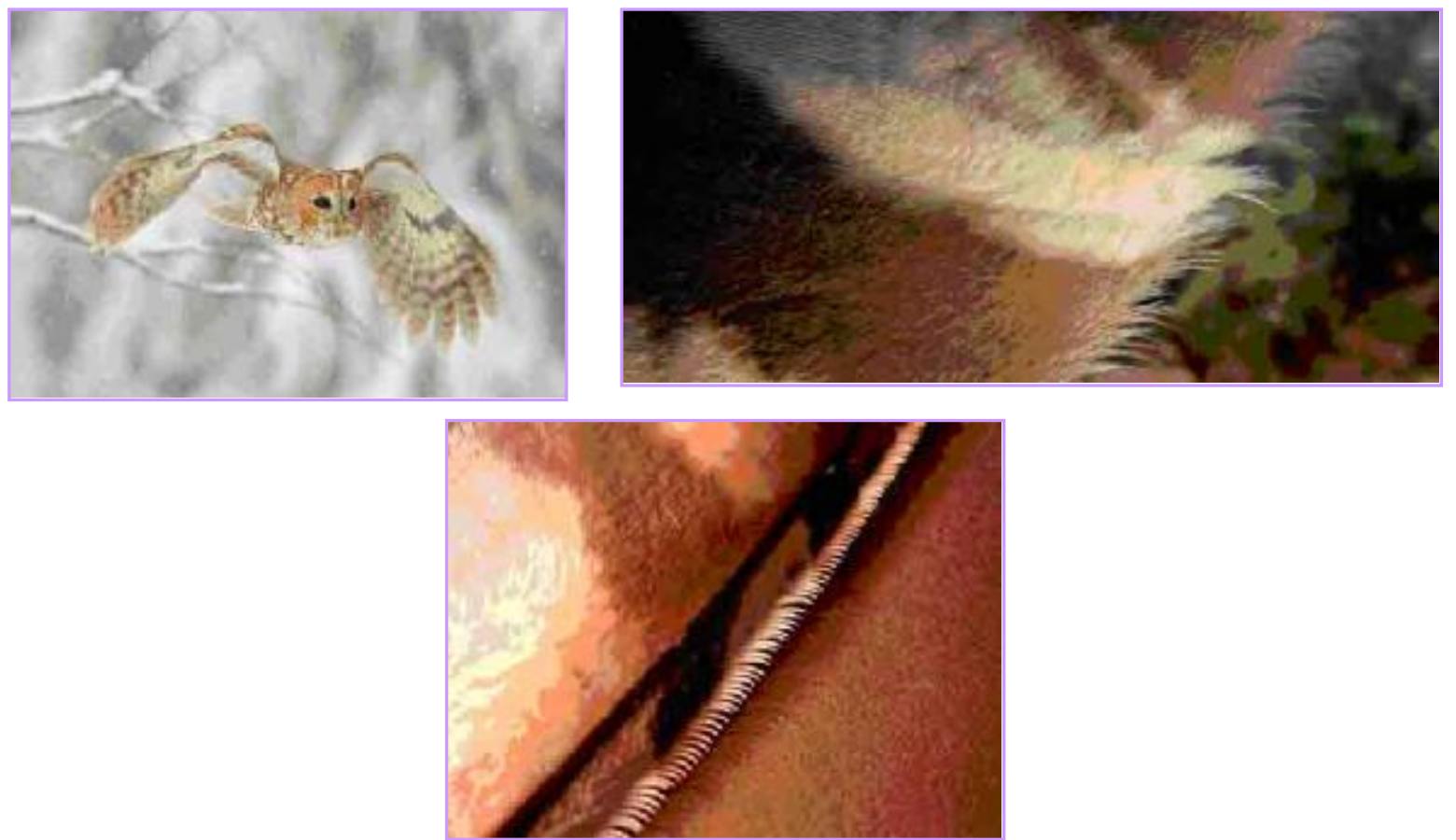

Fig. 4. The trailing and leading edge of an owl's feather reduces noise enable near-silent flight. Medicine

A mosquito's initial bite is actually quite painless. The highly serrated proboscis touches the nerves of the skin at fewer points than a smooth surface like a needle. Much less contact area translates into much less pain (as shown in fig. 5). Current needles are relatively smooth cylinders that present large amounts of surface area to nerves, causing pain to the human subject. Materials researchers and engineers at Kansai University in Japan saw amazing potential in the structure of the mosquito's mouth. They used sophisticated engineering techniques that can carve out structures on the nanometer scale. The result of this blend of materials science and biology was a needle that penetrates like a mosquito, using pressure to stabilize and painlessly glide into skin. This resulted in reduced pain for injecting or drawing blood samples.
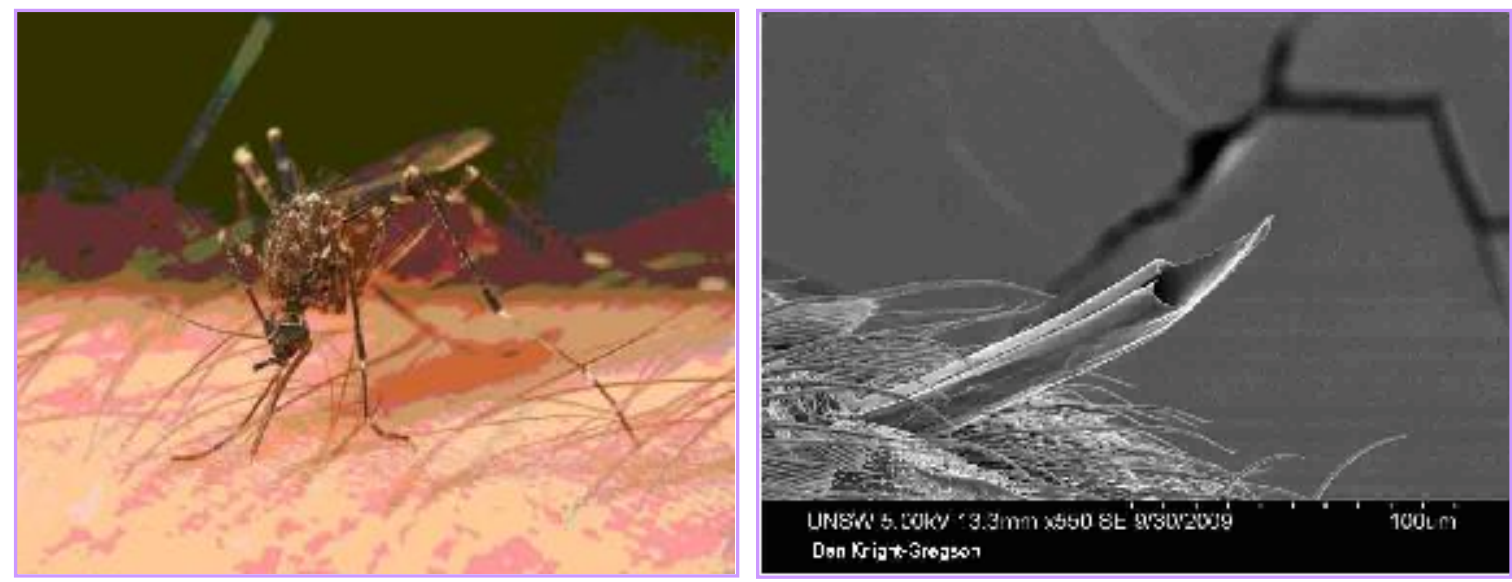

Fig. 5. (right) the proboscis of the Australian mosquito inserts painlessly because the jagged edge of the proboscis leaves only small points in contact. (left) View of the end of an Australian mosquito's proboscis.

\section{COMMUNICATIONS}

Earthquakes and the tsunamis they can generate cause deaths, long-term suffering by survivors, widespread devastation, and environmental damage in areas even far from the quake epicenter. An early detection system can prepare residents to evacuate even sooner, and perhaps take precautions to reduce damage to infrastructure. In order to reliably detect them 
and warn people before they reach land, sensitive pressure sensors must be located underneath passing waves in waters as deep as 6000 meters.

The data must then be transmitted up to a buoy at the ocean's surface, where it is relayed to a satellite for distribution to an early warning center. Transmitting data through miles of water has proven difficult, however, sound waves, while unique in being able to travel long distances through water, reverberate and destructively interfere with one another as they travel, compromising the accuracy of information. Dolphins are able to recognize the calls of specific individuals "signature whistles" up to 25 kilometers away, demonstrating their ability to communicate and process sound information accurately despite the challenging medium of water. By employing several frequencies in each transmission, dolphins have found a way to cope with the sound scattering behavior of their high frequency, rapid transmissions, and still get their message reliably heard. EvoLogic company developed and patented their Sweep Spread Carrier (S2C) technology to manage the challenging conditions presented by ocean waters. They developed underwater sensors that can transmit frequencies similar to those emitted by dolphins. These sensors can be used to detect underwater earthquakes and therefore aid in tsunami warning systems. They can also be used for guiding ships.

Energy

WhalePower company developed a new fan and wind turbine blade design (as shown in fig. 6) using Tubercle Technology. This was inspired by the flippers of humpback whales, which have tubercles or bumps on the leading edges.

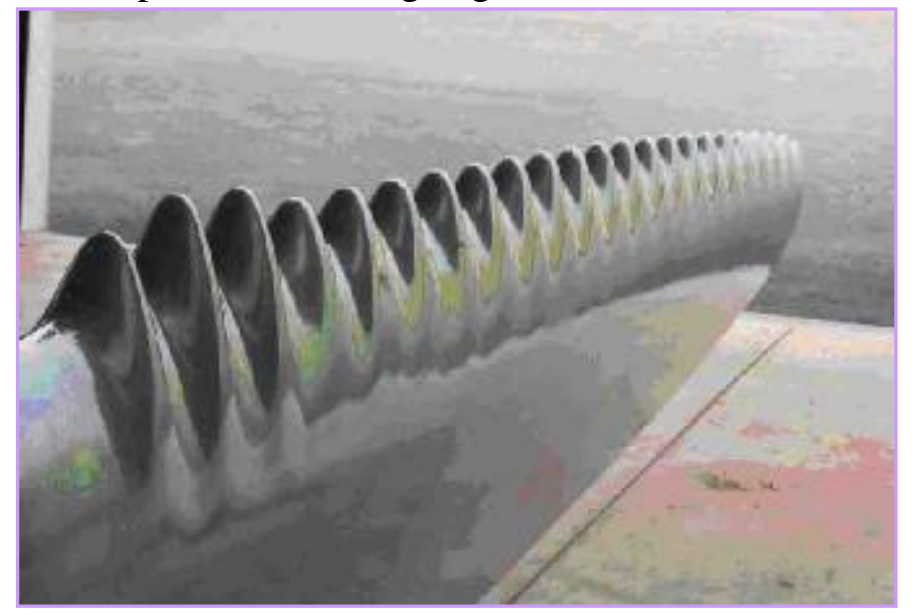

Fig. 6. WhalePower turbine blade.

Blades designed using Tubercle Technology are more energy efficient. Current wind turbine blades require steady, high winds to generate electricity. The efficiency of electric fans depends upon how much energy they need to move air.

A humpback whale (Megaptera novaeangliae) - 40-50 feet long and weighing nearly 80,000 pounds - swims in circles tight enough to produce nets of bubbles only 5 feet across while corralling and catching krill, its shrimp-like prey. It turns out that the whale's surprising dexterity is due mainly to its flippers, which have large, irregular looking bumps called tubercles across their leading edges (as shown in fig. 7). Whereas sheets of water flowing over smooth flippers break up into myriad turbulent vortices as they cross the flipper, sheets of water passing through a humpback's tubercles maintain even channels of fast-moving water, allowing humpbacks to keep their "grip" on the water at sharper angles and turn tighter corners, even at low speeds.

Wind tunnel tests of model humpback fins with and without tubercles have demonstrated the aerodynamic improvements tubercles make, such as an $8 \%$ improvement in lift and 32\% reduction in drag, as well as allowing for a $40 \%$ increase in angle of attack over smooth flippers before stalling. WhalePower Company is applying the lessons learned from humpback whales to the design of wind turbines to increase their efficiency, while this natural technology also has enormous potential to improve the safety and performance of airplanes, fans, and more. 


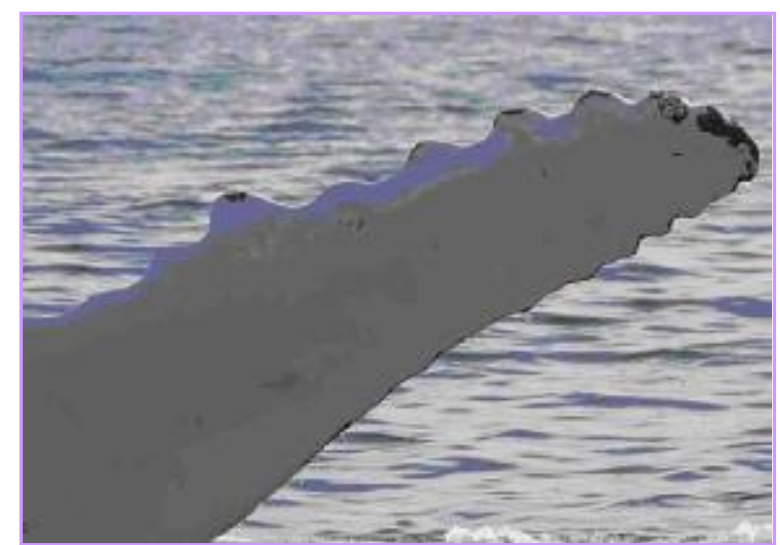

Fig. 7. Whales flippers with large irregular bumps called tubercles.

Approaches to Biomimicry

Approaches to biomimicry as a design process typically fall into two categories: Defining a human need or design problem and looking to the ways other organisms or ecosystems solve this, termed here design looking to biology, or identifying a particular characteristic, behavior or function in an organism or ecosystem and translating that into human designs, referred to as biology influencing design [21].

Design Looking into Biology

The approach where designers look to the living world for solutions, requires designers to identify problems and biologists to then match these to organisms that have solved similar issues. This approach is effectively led by designers identifying initial goals and parameters for the design. An example of such an approach is DaimlerChrysler's prototype Bionic Car (as shown in fig. 9). In looking to create a large volume, small wheel base car, the design for the car was based on the boxfish (ostracion meleagris), a surprisingly aerodynamic fish given its box like shape. The chassis and structure of the car are also biomimetic, having been designed using a computer modelling method based upon how trees are able to grow in a way that $\mathrm{n}$ is allc

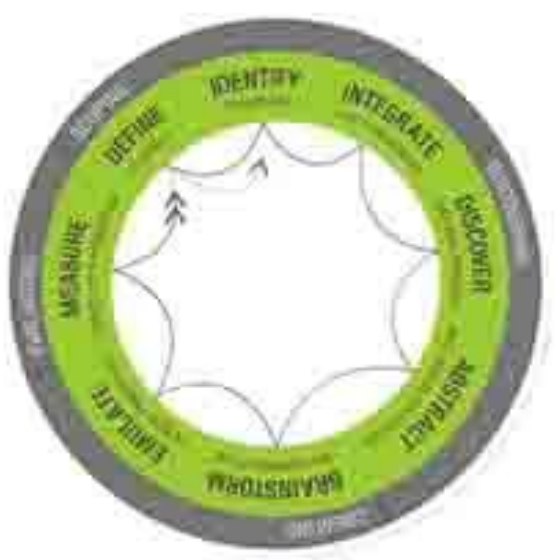
: resulting structure looks almost skeletal, as material mos

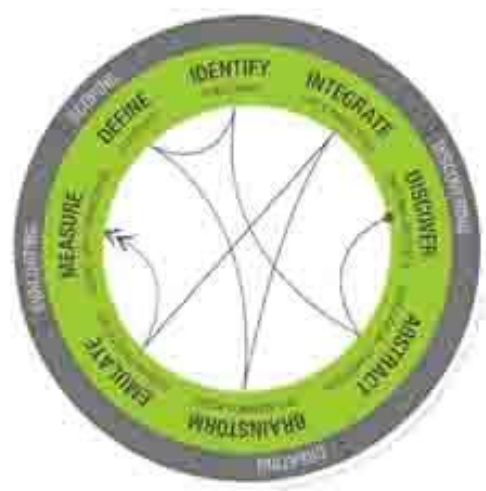

Fig. 8. biomimicry approaches; (left) design looking into biology, (right) biology influencing design.
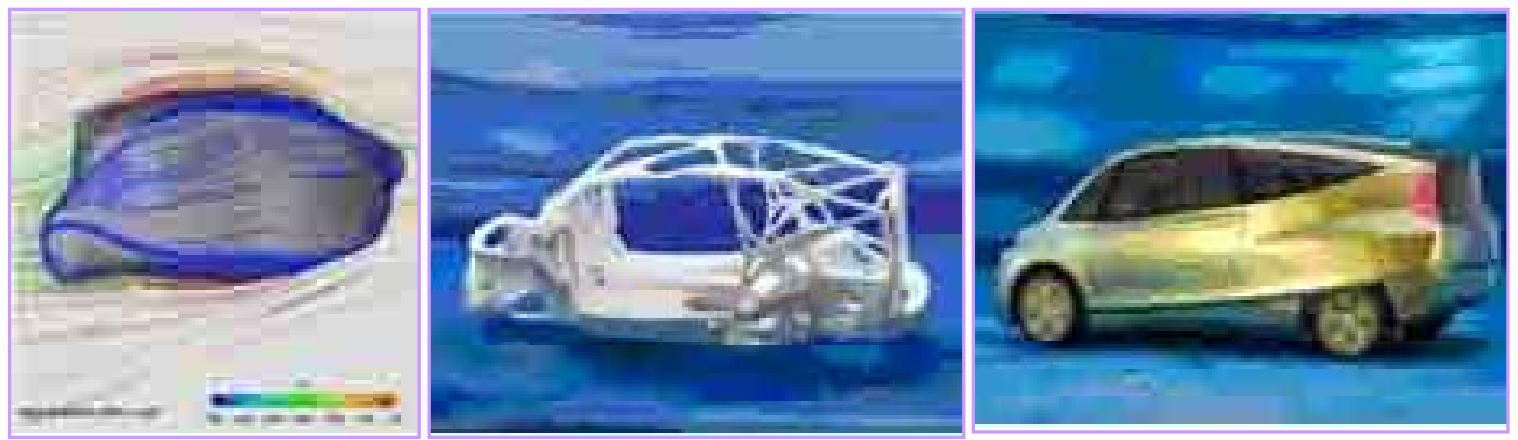

Fig. 9. Daimler Crysler bionic car inspired by the box fish and tree growth patterns. 
The possible implications of architectural design where biological analogues are matched with human identified design problems are that the fundamental approach to solving a given problem and the issue of how buildings relate to each other and the ecosystems they are part of is not examined. The underlying causes of a non-sustainable or even degenerative built environment are not therefore necessarily addressed with such an approach. The Bionic Car (fig. 9) illustrates the point. It is more efficient in terms of fuel use because the body is more aerodynamic due to the mimicking of the box fish. It is also more materials efficient due to the mimicking of tree growth patterns to identify the minimum amount of material need in the structure of the car. The car itself is however not a new approach to transport. Instead, small improvements have been made to existing technology without a re-examination of the idea of the car itself as an answer to personal transport.

Designers are able to research potential biomimetic solutions without an in-depth scientific understanding or even collaboration with a biologist or ecologist if they are able to observe organisms or ecosystems or are able to access available biological research. With a limited scientific understanding however, translation of such biological knowledge to a human design setting has the potential to remain at a shallow level. It is for example easy to mimic forms and certain mechanical aspects of organisms but difficult to mimic other aspects such as chemical processes without scientific collaboration. Despite these disadvantages, such an approach might be a way to begin transitioning the built environment from an unsustainable to efficient to effective paradigm [15]. Leading thinkers on regenerative design such as William Reed and Ray Cole argue however that a shift from a built environment that ultimately is degenerating ecosystems to one which regenerates capacity for ecosystems to thrive and restore local environments will not be a gradual process of improvements but will in fact require a fundamental rethinking of how architectural design is approached [11] [16].

Biology Influencing Design

When biological knowledge influences human design, the collaborative design process is initially dependent on people having knowledge of relevant biological or ecological research rather than on determined human design problems. An example is the scientific analysis of the lotus flower emerging clean from swampy waters, which led to many design innovations [17], including Sto's Lotusan paint which enables buildings to be self-cleaning (as shown in fig. 10).
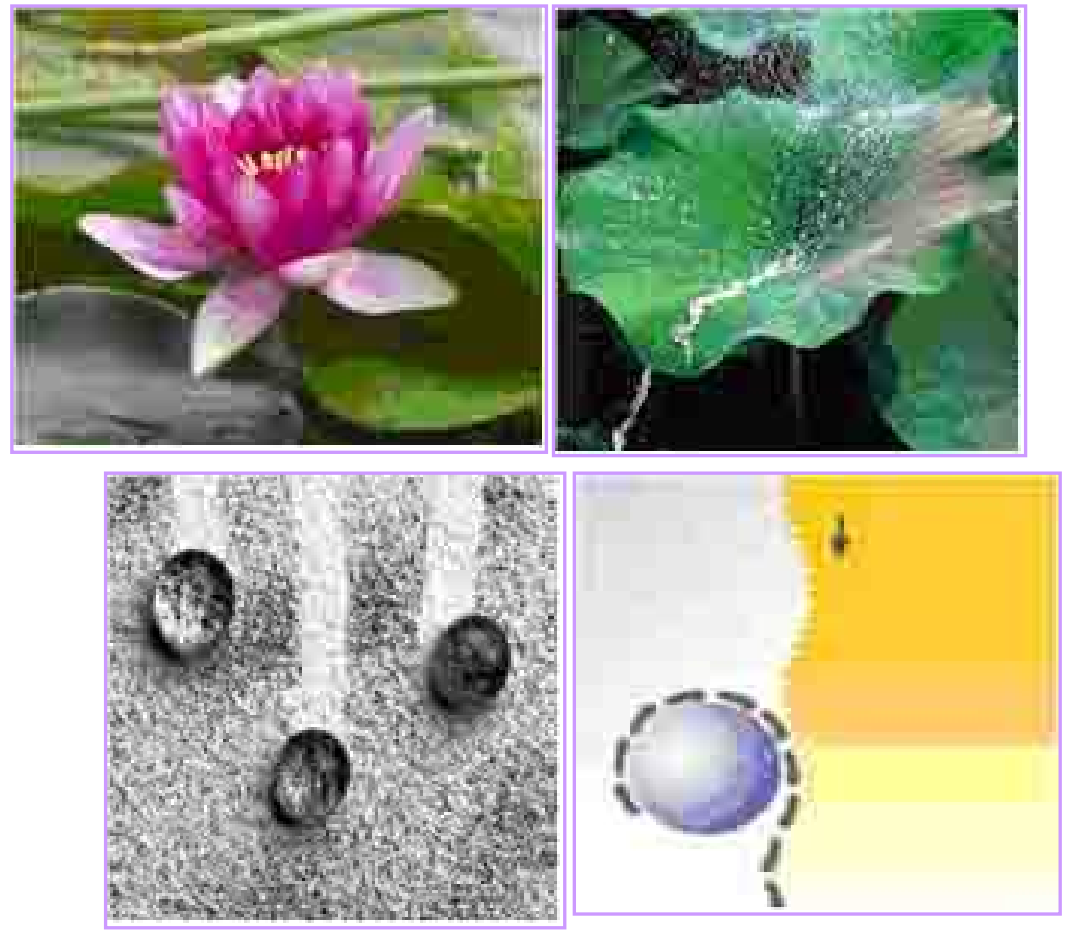

Fig. 10. Lotus Inspired Lotusan Paint 
It was pointed out that although humans as a species have been around for longer than the oldest living forest and are undoubtedly a learning and adaptable species, similarities between human design solutions and tactics used by other species, have a surprisingly small overlap considering they exist in the same context and with the same available resources [13] [18] [19]. An advantage of this approach therefore is that biology may influence humans in ways that might be outside a predetermined design problem, resulting in previously unthought-of technologies or systems or even approaches to design solutions. The potential for true shifts in the way humans design and what is focused on as a solution to a problem, exists with such an approach to biomimetic design [20]. A disadvantage from a design point of view with this approach is that biological research must be conducted and then identified as relevant to a design context. Biologists and ecologists must therefore be able to recognize the potential of their research in the creation of novel applications..

\section{Levels of Biomimicry Application}

Level of biomimicry determines which aspect of 'bio' has been 'mimicked'. This is referred to here as a level. Through an examination of existing biomimetic technologies, it is apparent that there are three levels of mimicry; the organism, behavior and ecosystem. The organism level refers to a specific organism like a plant or animal and may involve mimicking part of or the whole organism. The second level refers to mimicking behavior, and may include translating an aspect of how an organism behaves, or relates to a larger context. The third level is the mimicking of whole ecosystems and the common principles that allow them to successfully function.

Within each of these levels, a further five possible dimensions to the mimicry exist. The design may be biomimetic for example in terms of what it looks like (form), what it is made out of (material), how it is made (construction), how it works (process) or what it is able to do (function). The differences between each kind of biomimicry are described in Table 1 and are exemplified by looking at how different aspects of a termite, or ecosystem a termite is part of could be mimicked.

It is expected that some overlap between different kinds of biomimicry exists and that each kind of biomimicry is not mutually exclusive. For example, a series of systems that is able to interact like an ecosystem would be functioning at the ecosystem level of biomimicry. The individual details of such a system may be based upon a single organism or behavior mimicry however, much like a biological ecosystem is made up of the complex relationships between multitudes of single organisms.

Organism Level

Species of living organisms have typically been evolving for millions of years. Those organisms that remain on Earth now have the survival mechanisms that have withstood and adapted to constant changes over time. Humans therefore have an extensive pool of examples to draw on to solve problems experienced by society that organisms may have already addressed, usually in energy and materials effective ways. This is helpful for humans, particularly as access to resources changes, the climate changes and more is understood about the consequences of the negative environmental impact that current human activities have on many of the world's ecosystems [22].

An example is the mimicking of the Namibian desert beetle, stenocara [23]. The beetle lives in a desert with negligible rainfall. It is able to capture moisture however from the swift moving fog that moves over the desert by tilting its body into the wind. Droplets form on the alternating hydrophilic - hydrophobic rough surface of the beetle's back and wings and roll down into its mouth [24]. Matthew Parkes of KSS Architects demonstrates process biomimicry at the organism level inspired by the beetle, with his proposed fog-catcher design for the Hydrological Center for the University of Namibia (as shown in fig. 11) [25]. A more specific material biomimicry at the organism level is being discussed, where the surface of the beetle has been studied and mimicked to be used for other potential applications such as to clear fog from airport runways and improve dehumidification equipment for example [26] [27]. 
TABLE I. LEVELS AND MIMICRY DIMENSIONS FOR APPLICATION OF BIOMIMICRY (ADAPTED FROM PEDERSEN ZARI, 2007).

\begin{tabular}{|c|c|c|c|}
\hline $\begin{array}{r}\text { Leve } \\
\text { Bion } \\
\text { icr }\end{array}$ & nim & $\begin{array}{l}\text { Mimicry } \\
\text { Dimensions }\end{array}$ & \\
\hline \multirow{5}{*}{ 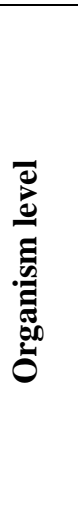 } & \multirow{5}{*}{ 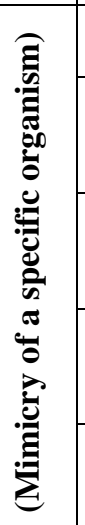 } & Form & The building looks like a termite. \\
\hline & & Material & $\begin{array}{l}\text { The building is made from the same material as a termite; a material that } \\
\text { mimics termite exoskeleton / skin for example. }\end{array}$ \\
\hline & & $\begin{array}{l}\text { Constructio } \\
\text { n }\end{array}$ & $\begin{array}{l}\text { The building is made in the same way as a termite; it goes through various } \\
\text { growth cycles for example. }\end{array}$ \\
\hline & & Process & $\begin{array}{l}\text { The building works in the same way as an individual termite; it produces } \\
\text { hydrogen efficiently through meta-genomics for example. }\end{array}$ \\
\hline & & Function & $\begin{array}{l}\text { The building functions like a termite in a larger context; it recycles cellulose } \\
\text { waste and creates soil for example. }\end{array}$ \\
\hline \multirow{5}{*}{ 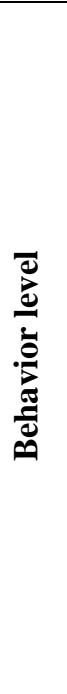 } & \multirow{5}{*}{ 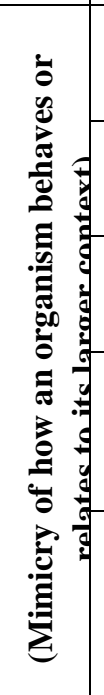 } & Form & $\begin{array}{l}\text { The building looks like it was made by a termite; a replica of a termite } \\
\text { mound for example. }\end{array}$ \\
\hline & & Material & $\begin{array}{l}\text { The building is made from the same materials that a termite builds with; } \\
\text { using digested fine soil as the primary material for example. }\end{array}$ \\
\hline & & $\begin{array}{l}\text { Constructio } \\
\text { n }\end{array}$ & $\begin{array}{l}\text { The building is made in the same way that a termite would build in; piling } \\
\text { earth in certain places at certain times for example. }\end{array}$ \\
\hline & & Process & $\begin{array}{l}\text { The building works in the same way as a termite mound would; by careful } \\
\text { orientation, shape, materials selection and natural ventilation for example, } \\
\text { or it mimics how termites work together. }\end{array}$ \\
\hline & & Function & $\begin{array}{l}\text { The building functions in the same way that it would if made by termites; } \\
\text { internal conditions are regulated to be optimal and thermally stable for } \\
\text { example. It may also function in the same way that a termite mound does in } \\
\text { a larger context. }\end{array}$ \\
\hline \multirow{5}{*}{ 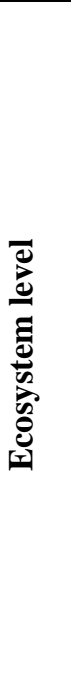 } & \multirow{5}{*}{ 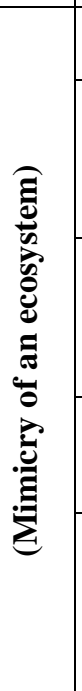 } & Form & The building looks like an ecosystem (a termite would live in). \\
\hline & & Material & $\begin{array}{l}\text { The building is made from the same kind of materials that (a termite) } \\
\text { ecosystem is made of; it uses naturally occurring common compounds, and } \\
\text { water as the primary chemical medium for example. }\end{array}$ \\
\hline & & $\begin{array}{l}\text { Constructio } \\
\text { n }\end{array}$ & $\begin{array}{l}\text { The building is assembled in the same way as a (termite) ecosystem; } \\
\text { principles of succession and increasing complexity over time are used for } \\
\text { example. }\end{array}$ \\
\hline & & Process & $\begin{array}{l}\text { The building works in the same way as a (termite) ecosystem; it captures } \\
\text { and converts energy from the sun, and stores water for example. }\end{array}$ \\
\hline & & Function & $\begin{array}{l}\text { The building is able to function in the same way that a (termite) ecosystem } \\
\text { would and forms part of a complex system by utilizing the relationships } \\
\text { between processes; it is able to participate in the hydrological, carbon, } \\
\text { nitrogen cycles etc in a similar way to an ecosystem for example. }\end{array}$ \\
\hline
\end{tabular}



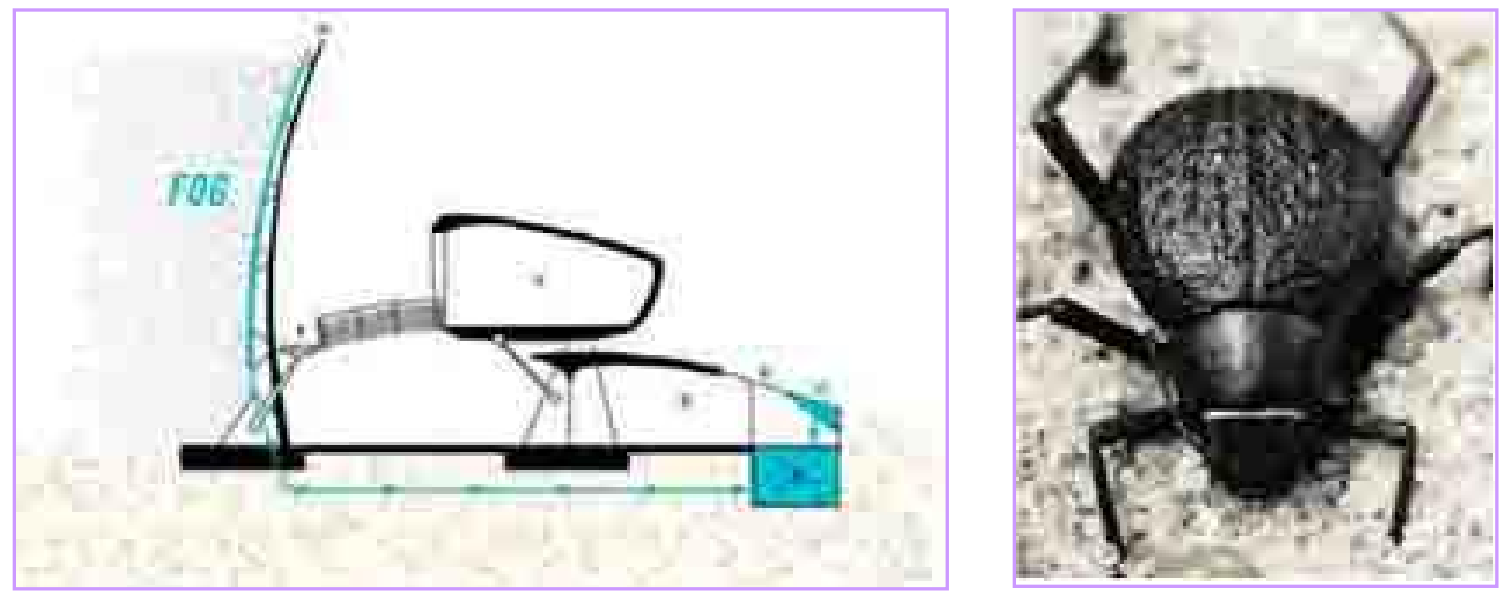

Fig. 11. Matthew Parkes' Hydrological Center for the University of Namibia and the stenocara beetle.

Nicholas Grimshaw \& Partners' design for the Waterloo International Terminal demonstrates an example of form and process biomimicry at the organism level (as shown in fig. 12). The terminal needed to be able to respond to changes in air pressure as trains enter and depart the terminal. The glass panel fixings that make up the structure mimic the flexible scale arrangement of the Pangolin so they are able to move in response to the imposed air pressure forces [28].

Mimicking an organism alone however without also mimicking how it is able to participate in and contribute to the larger context of the ecosystem it is in, has the potential to produce designs that remain conventional or even below average in terms of environmental impact [29]. Because mimicking of organisms tends to be of a specific feature, rather than a whole system, the potential also remains that biomimicry becomes technology that is added onto buildings rather than being integral to them, particularly if designers have little biological knowledge and no not collaborate with biologists or ecologists during the early design stages. While this method may result in new and innovative building technologies or materials, methods to increase sustainability are not necessarily explored.
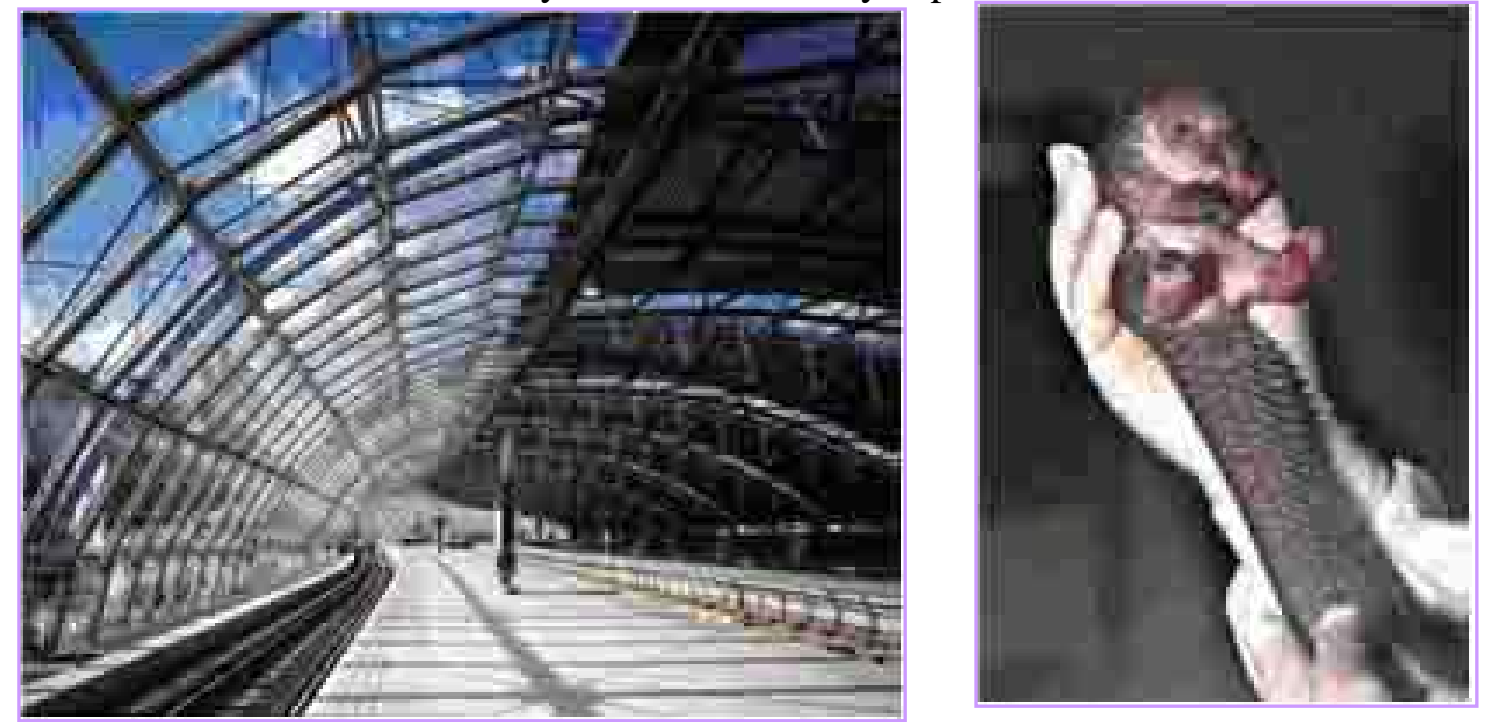

Fig. 12. Nicholas Grimshaw \& Partners' Waterloo International Terminal and the pangolin. 


\section{Behavior Level}

A great number of organisms encounter the same environmental conditions that humans do and need to solve similar issues that humans face. As discussed, these organisms tend to operate within environmental carrying capacity of a specific place and within limits of energy and material availability. These limits as well as pressures that create ecological niche adaptations in ecosystems mean not only well-adapted organisms continue to evolve, but also well-adapted organism behaviors and relationship patterns between organisms or species [29]. Organisms that are able to directly or indirectly control the flow of resources to other species and who may cause changes in biotic or abiotic (non-living) materials or systems and therefore habitats are called ecosystem engineers [30] [31]. Ecosystem engineers alter habitat either through their own structure (such as coral) or by mechanical or other means (such as beavers and woodpeckers). Humans are undoubtedly effective ecosystem engineers, but may gain valuable insights by looking at how other species are able to change their environments while creating more capacity for life in that system. Several authors provide examples and details of organisms altering their own habitats while facilitating the presence of other species, increasing nutrient cycling and creating mutually beneficial relationships between species. The building behavior of other species is often termed 'animal architecture' [32] [33] and may provide further examples of such ecosystem engineers.

The example of the North American beaver (castor canadensis) (shown in fig. 13) demonstrates how through its altering of the landscape, wetlands are created and nutrient retention and plant and animal diversity is increased, helping in part to make the ecosystem more resilient to disturbance [31].
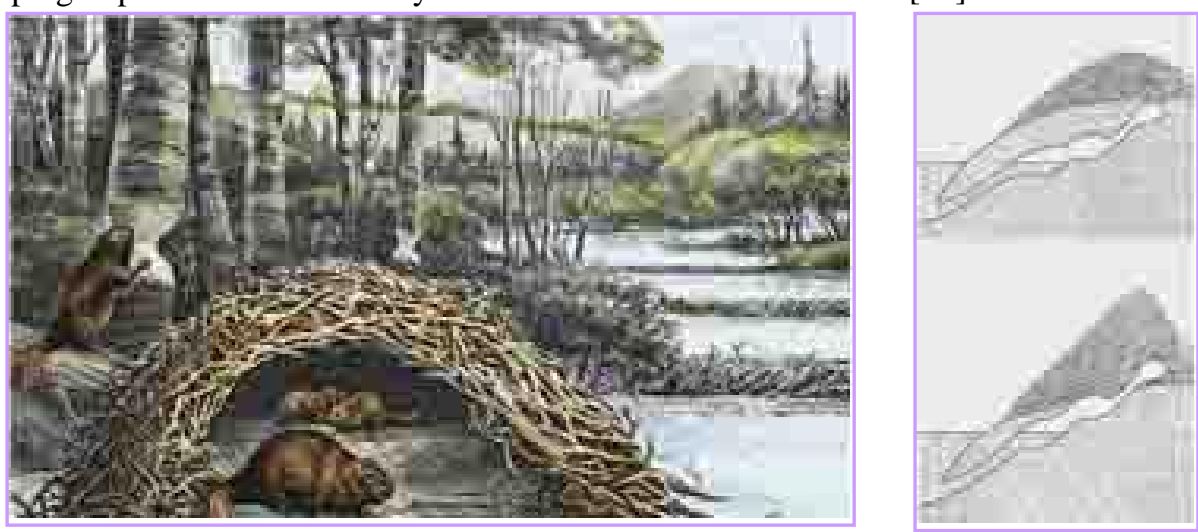

Fig. 13. The North American Beaver

In behavior level biomimicry, it is not the organism itself that is mimicked, but its behavior. It may be possible to mimic the relationships between organisms or species in a similar way. An architectural example of process and function biomimicry at the behavior level is demonstrated by Mick Pearce's Eastgate Building in Harare, Zimbabwe and the $\mathrm{CH} 2$ Building in Melbourne, Australia (shown in fig. 14). Both buildings are based in part on techniques of passive ventilation and temperature regulation observed in termite mounds, in order to create a thermally stable interior environment. Water which is mined (and cleaned) from the sewers beneath the $\mathrm{CH} 2$ Building is used in a similar manner to how certain termite species will use the proximity of aquifer water as an evaporative cooling mechanism.
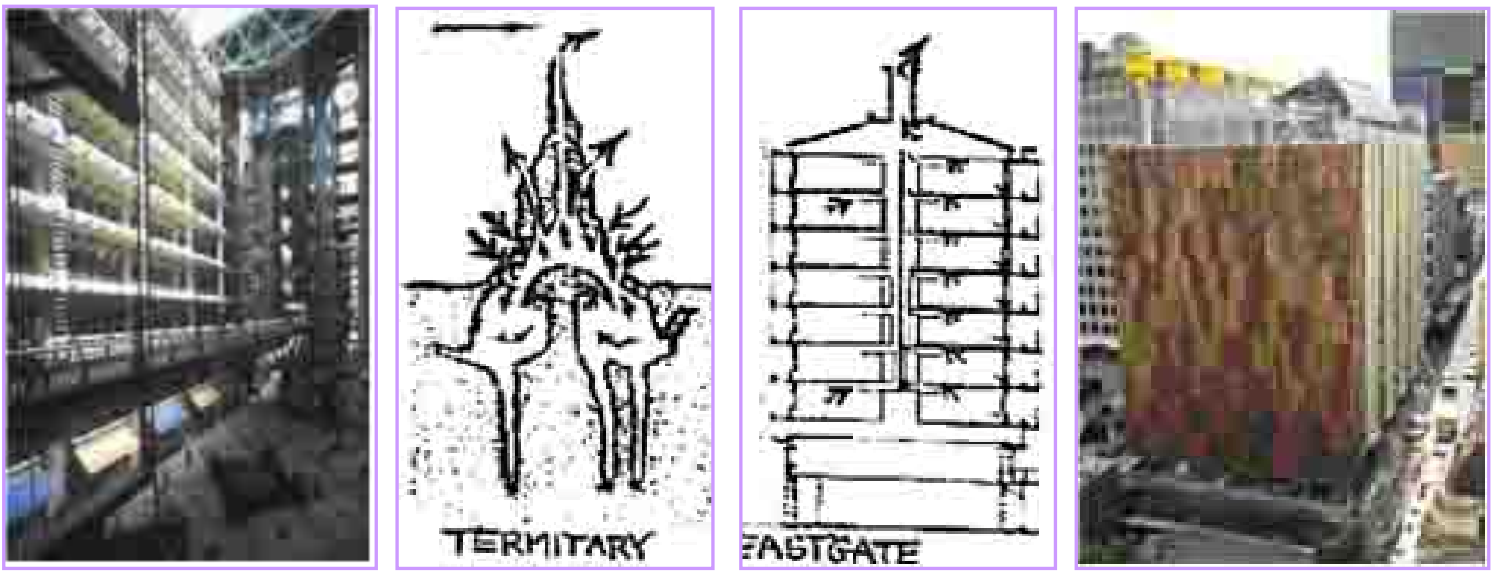

Fig.14. Eastgate Building in Harare, Zimbabwe and CH2 Building in Melbourne, Australia 
Behavior level mimicry requires ethical decisions to be made about the suitability of what is being mimicked for the human context. Not all organisms exhibit behaviors that are suitable for humans to mimic and the danger exists that models of consumption or exploitation could be justified on the basis of how another species behaves. For example, mimicking the building behavior (and outcome of that) of termites might be appropriate for the creation of passively regulated thermally comfortable buildings. Mimicking the social structure of termite colonies would not be suitable however if universal human rights are valued. It may be more appropriate to mimic specific building and survival behaviors that will increase the sustainability and regenerative capacity of human built environments rather than mimicking that could be applied to social or economic spheres without careful consideration. It may be more appropriate to mimic whole systems rather than single organisms in this regard. An example is [34]' assertion that we should 'do business like a redwood forest'.

\section{Ecosystem Level}

The mimicking of ecosystems is an integral part of biomimicry as described by [34] and [35]. The term ecomimicry has also been used to describe the mimicking of ecosystems in design [36] [37], while [38] uses the term to mean a sustainable form of biomimicry where the objective is the wellbeing of ecosystems and people, rather than 'power, prestige or profit'. Proponents of industrial, construction and building ecology advocate mimicking of ecosystems [39] [40] [41] and the importance of architectural design based on an understanding of ecology is also discussed by researchers advocating a shift to regenerative design [42].

The most important advantage of such an approach to biomimetic design may be the potential positive effects on overall environmental performance. Ecosystem based biomimicry can operate at both a metaphoric level and at a practical functional level. At a metaphoric level, general ecosystem principles (based on how most ecosystems work) are able to be applied by designers with little specific ecological knowledge. Several authors have offered such general principles [34] [15] [43]. A set of ecosystem principles derived from comparing these cross disciplinary understandings of how ecosystems function is detailed by [44]. If the built environment was designed to be a system and was expected to behave like an ecosystem even if only at the level of metaphor, the environmental performance of the built environment may increase [41].

On a functional level, ecosystem mimicry could mean that an in-depth understanding of ecology drives the design of a built environment that is able to participate in the major biogeochemical material cycles of the planet (hydrological, carbon, nitrogen etc) in a reinforcing rather than damaging way [45]. That a greater understanding of ecology and systems design is required on the part of the design team is implicit. Also required would be increased collaboration between disciplines that traditionally seldom work together such as architecture, biology and ecology. Such an approach challenges conventional architectural design thinking, particularly the typical boundaries of a building site and time scales a design may operate in.

While [46] cites a number of authors advocating similar ideas, he criticizes this kind of approach to design, because of the difficulty in understanding and modelling ecosystems and asserts that '...the mimicking of nature in human designs is one dimensional [and] noncomplex...' This is true in terms of realized built form, but does not suggest that mimicking what is known about ecosystems is not a worthy goal in terms of increasing sustainability or indeed that it is impossible, particularly when one takes into account that biological knowledge may be doubling every 5 years [34].

\section{Adaptation Solutions in Nature}

As architects and engineers try to maintain a comfort state inside the buildings despite the changes of the environmental conditions, many living organisms seek physiologically tolerable conditions (what humans call "comfort"), called homeostasis in biology. Homeostasis is one of the fundamental characteristics of living organisms. There are several factors that are constantly regulated by the body of an organism to achieve homeostasis, including: concentrations of nutrients, oxygen, salts, wastes, heat, pressure, and volume [47]. These factors are manipulated through the following processes for homeostasis:

- Gas regulation: Respiration / Ventilation 
- Water and osmotic regulation: Osmoregulation

- Heat regulation: Thermoregulation

Living organisms have developed through evolution adaptation strategies to cope with different environmental aspects. Their adaptation may occur at various scales of time: throughout the day (e.g. solar tracking by sunflowers); throughout the seasons (e.g. seasonal changes in blubber distribution in seals [48]); or throughout evolution (e.g. human skin color). Adaptation is especially obvious in the organisms able to survive harsh and challenging environment conditions. These environments are called extreme environments, because of their extreme influential factors, which include: extremes of temperature, humidity, solar radiation, pressure, and other environmental factors. Such factors have necessitated the evolution of unique adaptations in terms of physiology, morphology, and behavior [49]; the physiological and morphological adaptations reflect functional features that help organisms to adapt to their environment, whereas behavioral adaptations relate to the actions done by organisms in order to survive. Each of these is discussed in more detail below.

Physiological Adaptation

Physiological adaptation is "an organismic or systemic response of an individual to a specific external stimulus in order to maintain homeostasis" [Biology-online dictionary].

"Basically, homeostasis can be considered paramount for the successful adaptation of the individual to dynamic environments, hence essential for survival" [50]. Physiology is about the regulation of the different functions that allow them to adjust to the environmental changes - "how they are correlated and integrated into a smooth-functioning organism" [51]. An example for a physiological adaptation is the salinity tolerance of the mangroves. Mangroves (as shown in fig. 15, (left) inhabit the inter-tidal zones along the coast with a high salinity level. Biochemical and molecular mechanisms enable mangroves to cope with salt stress, for example: "control of ion uptake by roots and transport into leaves" [52], (as shown in fig. 15, (right)).
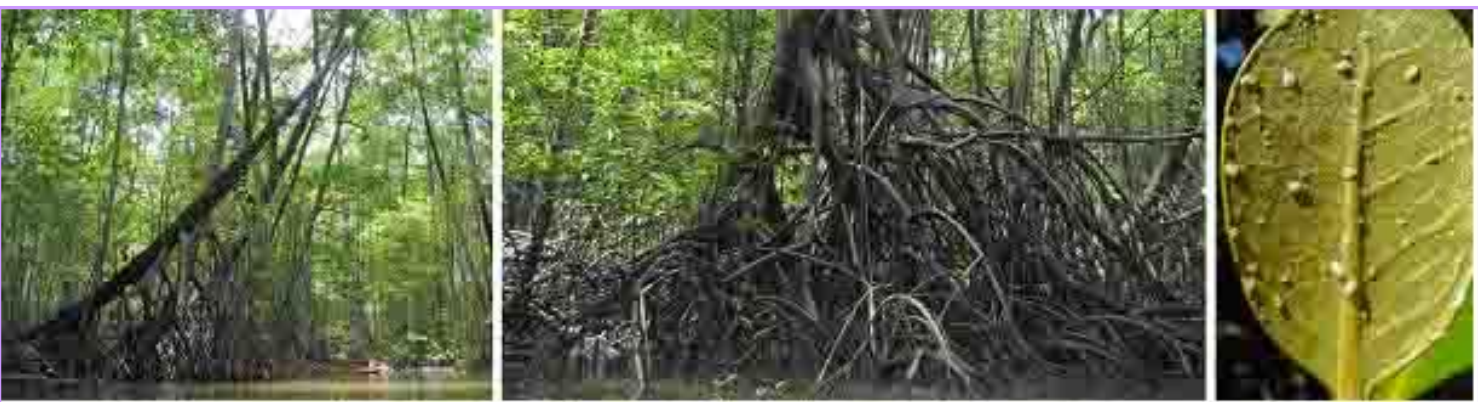

Fig.15. (Left): Mangrove habitat, Costa Rica. (Right): the deposition of salt in the form of crystals on

\section{Morphological Adaptation}

older leaves close to falling, [53].

Morphological adaptation is a structural feature that enhances the adjustment of organisms to their particular environment and enables better functionality for survival. Various structural features influence organism adaptation, among which are size, form, color, and pattern. The special form of stem, small and thin leaves, and extensive root system are a good example for morphological adaptation among desert plants (as shown in fig. 16). Such stems allow water storage and self-shading situation, small leaves reduce water loss, and the extensive root system enables the plant to collect as much moisture as possible.
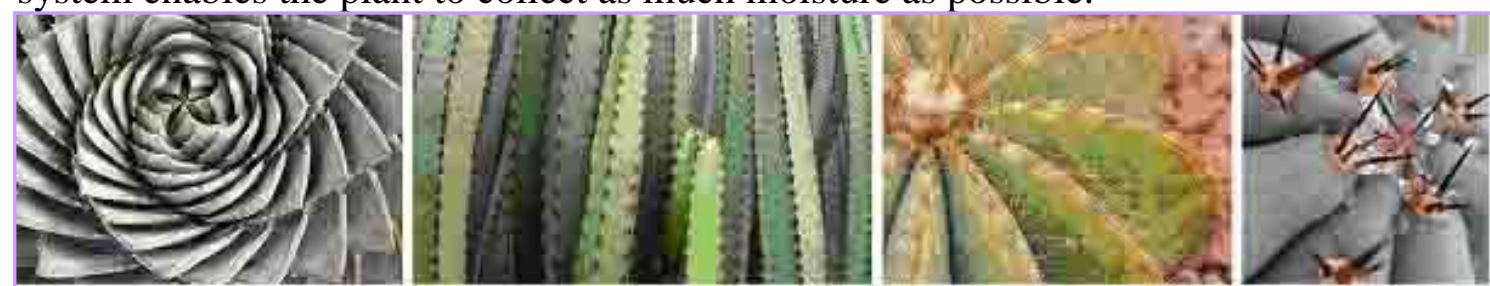

Fig.16. Morphological variations in cacti. Images courtesy (from left to right): [54] [55] [56] [57]. 


\section{Behavioral Adaptation}

Behavioral adaptation is the actions organisms take for survival. For example, birds migrate, squirrels hibernate, and social insects exhibit swarm behavior. This type of adaptation is linked to a signal feedback system of signal and response, where behavior marks an interaction between the organism and its environment. In this context, [58] interprets adaptation as "equilibrium between the action of the organism on the environment and vice versa". It is emphasized that an action takes place for necessity, "i.e., if the equilibrium between the environment and the organism is momentarily upset, and action tends to re-establish the equilibrium" [58]. In order to cope with the new situations that the environment generates, the organism can behave accordingly by reacting to stimuli (from the surrounding environment), create an appropriate response, and execute that response for an optimal result. Various examples can be found in nature for such behavior. For example, penguins huddle together during snowstorms thereby reducing surface area and decreasing heat loss (as shown in fig.17).

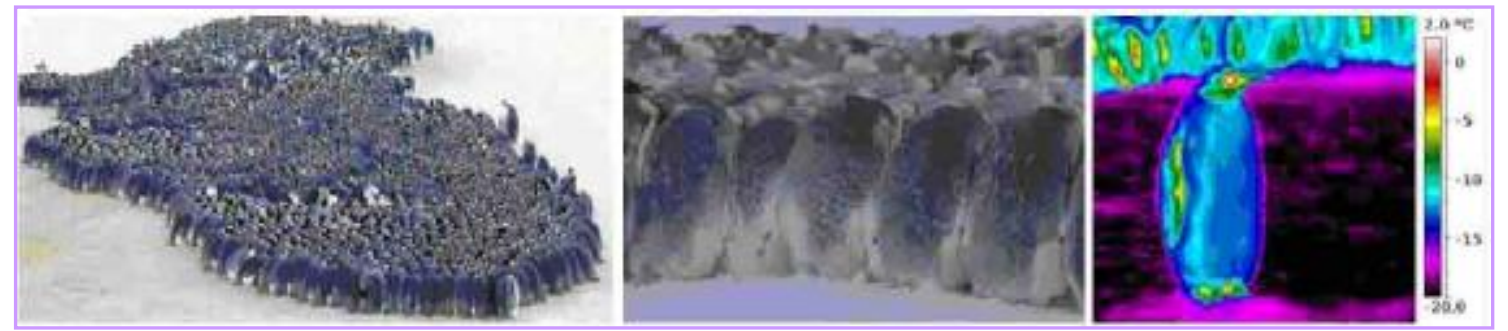

Fig. 17. (Left): a group of huddling penguins, which consists of about 2500 males, [59]. (Middle): a closer view of huddling penguins. (Right): infrared image of penguin [60], photo credit: Université de Strasbourg and Centre National de la Recherche Scientifique (CNRS), Strasbourg, France

\section{CONCLUSION}

Seeking solutions or analogies from nature is a widely growing practice in research, yet practical applications to buildings for environmental adaptation are still limited. This paper aims discuss biomimicry as an adaptive approach to help develop new technological solutions inspired by nature to enhance the environmental adaptation capability of building systems.

It is hoped that designers would thus consider the underlying environmental processes of distinct organisms and ecosystems at the initial stages of a design process and take inspiration from their adaptation mechanisms. This would promote the development of adaptive solutions for building envelopes.

\section{REFERENCES}

[1] Benyus, J.M. Biomimicry: Innovation Inspired by Nature; Harper Perennial: New York, NY, USA, 2002.

[2] Salgueiredo, C. F., \& Hatchuel, A. (2016). Beyond analogy: A model of bioinspiration for creative design. AI EDAM, 30(2), 159-170.

[3] Badarnah, L. (2009). Bio-Mimic to Realize! Biomimicry for Innovation in Architecture; The architecture annual 2007-2008. Delft University of Technology: Rotterdam, The Netherlands, 54-59.

[4] Garcia-Holguera, M., Clark, O. G., Sprecher, A., \& Gaskin, S. (2016). Ecosystem biomimetics for resource use optimization in buildings. Building Research \& Information, 44(3), 263-278.

[5] Xing, Y., Jones, P., \& Donnison, I. (2017). Characterisation of nature-based solutions for the built environment. Sustainability, 9(1), 149.

[6] Badarnah, L. (2012). Towards the LIVING envelope: biomimetics for building envelope adaptation (Doctoral dissertation, Delft University of Technology).

[7] Gamage, A., \& Hyde, R. (2012). A model based on Biomimicry to enhance ecologically sustainable design. Architectural Science Review, 55(3), 224-235.

[8] Mazzoleni, I. (2013). Architecture follows nature-biomimetic principles for innovative design. Crc Press.

[9] Pawlyn, M. Biomimicry in Architecture; Riba Publishing: Marylebone, UK, 2011. 
[10] Zari, M. P. (2010). Biomimetic design for climate change adaptation and mitigation. Architectural Science Review, 53(2), 172-183.

[11] Reed, B. (2006) Shifting our Mental Model - "Sustainability" to Regeneration. Rethinking Sustainable Construction 2006: Next Generation Green Buildings. Sarasota, Florida.

[12] Berkebile, B.(2007) Master Speaker Address. Living Future Conference. Seattle, WA.

[13] Vincent, J. F. V., Bogatyrev, O. A., Bogatyrev, N. R., Bowyer, A. \& Pahl, A.-K. (2006) Biomimetics - its practice and theory. Journal of the Royal Society Interface, April 2006.

[14] Baumeister, D. (2007b) Evolution of the Life's Principles Butterfly Diagram, personal communication, April.

[15] McDonough, W. \& Braungart, M. (2002) Cradle to Cradle - Remaking the Way We Make Things, New York, North Point Press.

[16] Cole, R., Reed, W. \& Du Plessis, C. (2007) Friday Theme Session Panel. AIA 2007 National Convention and Expo. San Antonio, Texas.

[17] Baumeister, D. (2007a) Biomimicry Presentation at the University of Washington College of Architecture. Seattle, USA. 8 May.

[18] Hawken, P. (2007) Blessed Unrest, New York, Viking Press.

[19] Vogel, S. (1998) Cat's Paws and Catapults, New York, Norton and Company.

[20] Vincent, J. F. V., Bogatyrev, O., Pahl, A.-K., Bogatyrev, N. R. \& Bowyer, A. (2005) Putting Biology into TRIZ: A Database of Biological Effects. Creativity and Innovation Management, 14, 66-72.

[21] Biomimicry Guild (2007) Innovation Inspired by Nature Work Book, Biomimicry Guild, April.

[22] Alberti, M., Marzluff, J. M., Shulenberger, E., Bradley, G., Ryan, C. \& Zumbrunnen, C. (2003) Integrating Humans into Ecology: Opportunities and Challenges for Studying Urban Ecosystems. Bioscience, 53, 1169-1179.

[23] Garrod, R. P., Harris, L. G., Schofield, W. C. E., McGettrick, J., Ward, L. J., Teare, D. O. H. \& Badyal, J. P. S. (2007) Mimicking a Stenocara Beetle's Back for Microcondensation Using Plasmachemical Patterned Superhydrophobic- Superhydrophilic Surfaces. Langmuir, 23, 689-693.

[24] Parker, A. R.\& Lawrence, C.R.(2001) Water capture by a desert beetle. Nature,414,33

[25] Killeen, M. (2002) Water Web. Metropolis Magazine, May.

[26] Knight, W. (2001) Beetle fog-catcher inspires engineers. New Scientist, 13, 38.

[27] Ravilious, K. (2007) Borrowing from Nature's Best Ideas. The Guardian, July 31.

[28] Aldersey-Williams, H. (2003) Zoomorphic - New Animal Architecture, London, Laurence King Publishing.

[29] Reap, J., Baumeister, D. \& Bras, B. (2005) Holism, Biomimicry and Sustainable Engineering. ASME International Mechanical Engineering Conference and Exposition. Orlando, FL, USA.

[30] Jones, C. G. \& LAWTON, J. H. (1995) Linking Species and Ecosystems, New York, Chapman and Hall.

[31] Rosemond, A. D. \& Anderson, C. B. (2003) Engineering Role Models: Do Non-Human Species have the Answers? Ecological Engineering, 20, 379-387.

[32] von Frisch, K. \& von Frisch, O. (1974) Animal Architecture, New York, Helen and Kurt Wolff Books.

[33] Hansell, M. (2005) Animal Architecture, New York, Oxford University Press.

[34] Benyus, J. (1997) Biomimicry - Innovation Inspired by Nature, New York, Harper Collins Publishers.

[35] Vincent, J. (2007) Re: Designing around existing patents through TRIZ, personal email communication, 5 May

[36] Russell, J. A. (2004) Evaluating the Sustainability of an Ecomimetic Energy System: An Energy Flow Assessment of South Carolina. Department of Mechanical Engineering. University of South Carolina.

[37] Lourenci, A., Zuffo, J. A. \& Gualberto, L. (2004) Incipient Emergy Expresses the SelfOrganisation Generative Activity of Man-Made Ecomimetic Systems. In Ortega, E. \& Ulgiati, S. (Eds.) IV Biennial International Workshop. Advances in Energy Studies. Campinas, Brazil. 
[38] Marshall, A. (2007) The Ecomimicry Project. Accessed May 2007, http://www.geocities.com/ecomimicryproject/

[39] Graham, P. (2003) Building Ecology - First Principles for a Sustainable Built Environment, Oxford, Blackwell Publishing.

[40] Kibert, C. J., Sendzimir, J. \& Guy, G. B. (2002) Construction Ecology, New York, Spon Press.

[41] Korhonen, J. (2001) Four Ecosystem Principles for an Industrial Ecosystem. Journal of Cleaner Production, 9, 253-259.

[42] Reed, B. (2006) Shifting our Mental Model - "Sustainability" to Regeneration. Rethinking Sustainable Construction 2006: Next Generation Green Buildings. Sarasota, Florida.

[43] De Groot, R., Wilson, M. A. \& Boumans, R. M. J. (2002) A Typology for the Classification, Description and Valuation of Ecosystem Function, Goods and Services. Ecological Economics, 41, 393-408.

[44] Pedersen Zari, M. \& Storey, J. B. (2007) An Ecosystem Based Biomimetic Theory for a Regenerative Built Environment. Lisbon Sustainable Building Conference 07. Lisbon, Portugal.

[45] Charest, S. (2007) Ecosystem Principle Research, personal communication, May.

[46] Kibert, C. J. (2006) Revisiting and Reorienting Ecological Design. Construction Ecology Symposium. Massachusetts Institute of Technology, Cambridge, MA.

[47] Hill, R.W., Wyse, G.A., and Andreson, M., [2008]. Animal Physiology, Massachusetts: Sinauer Associates Inc.

[48] Rosen, D.A.S. \& Renouf, D., [1997]. Seasonal changes in blubber distribution in atlantic harbor eals: indication of thermodynamic considerations. Marine Mammal Science, 13(2), pp. 229-240.

[49] Louw, G.N. \& Seely, M.K., [1982], Ecology of Desert Organisms, London: Longman Group Ltd.

[50] Vargas, P.A., Moioli, R.C., von Zuben, F.J., and Husbands, P., [2009]. Homeostasis and evolution together dealing with novelties and managing disruptions. International Journal of Intelligent Computing and Cybernetics, 2(3), pp. 435-454.

[51] Schmidt-Nielsen, K., [2007], Animal physiology: adaptation and environment, New York: Cambridge University Press.

[52] Parida, A.K. \& Das, A.B., [2005]. Salt tolerance and salinity effects on plants: a review. Ecotoxicology and Environmental Safety, 60, pp. 324-349.

[53] Peripitus [2006]. Photo taken on the mangrove walk St Kilda, South Australia, available online at: http://en.wikipedia.org/wiki/File:Saltcrystals on avicennia marina_var_resinifera_leaves.JPG (retrieved July 2012).

[54] Axsom D. [2006]. Aloe polyphylla in the San Francisco Botanical Garden (formerly Strybing Arboretum), available online at: http://commons.wikimedia.org/wiki/File :Succulent_spiral.jpg (retrieved September 2012).

[55] Eisenberg P.J. [2009]. Cleistocactus sepium (syn'Borzicactus websterianus) and other tall cacti, Huntington Library Desert Botanical Garden in afternoon after and during rain, February 2009 - Various cactus and succulent plants, available online at: http://commons.wikimedia.org/wiki/File:Borzicactus_Websteramus,_Cleistocactus,_Huntin gton_Desert_Garden.jpg (retrieved September 2012).

[56] Johansson C.T. [2010]. Okänd kaktus, available online at: http://commons. wikimedia.org/wiki/File:2811_cactus.jpg (retrieved September 2012).

[57] Mattdooley40 [2010]. Dew on cactus spines, available online at: http://www.flickr.com/photos/59893103@N05/5491570029/in/photostream (retrieved September 2012).

[58] Piaget, J., [1967], (1947 in French). The Psychology of intelligence, Piercy M. trans., London: Routledge \& Kegan Paul Limited.

[59] Gilbert, C.; Robertson, G.; Le Maho, Y.; Naito, Y.; Ancel, A. Huddling behavior in emperor penguins: Dynamics of huddling. Physiol. Behav. 2006, 88, 479-488.

[60] Mccafferty, D.J.; Gilbert, C.; Thierry, A.-M.; Currie, J.; Le Maho, Y.; Ancel, A. Emperor penguin body surfaces cool below air temperature. Biol. Lett. 2013, 9, 20121192. 